\title{
La escena teatral como dispositivo de pensar la realidad. Los estudios literarios y teatrales en el marco del pensar postmoderno*
}

\author{
Marta Contreras Bustamante \\ Universidad de Concepción \\ E-mail: mcontre@udec.cl
}

E N EL Grupo de Investigación de Literatura C hilena M ECESU P 0203 esta- mos compartiendo al gunas reflexiones relativas a los enfoques y parámetros de acercamiento a los estudios literarios en general, en Latinoamérica, en Chile.

$H$ emos conectado esta reflexión a una práctica en la que estamos hace varios años y que pretende insertar dispositivos que modifican los escenarios educativos tradicionales propios de la modernidad.

Esta práctica consiste en el cuestionamiento y reformulación dela noción de cuerpo, por una parte, y, por otra, en la proposición que postula invitar a ese cuerpo a entrar en la escena educativa. En este proceso hemos dejado algunos asuntos pendientes y no explicitados por el temor de meternos en camisa de once varas y tal vez también esperando condiciones más propicias.

Ahora, a través de la constitución de este grupo y de la mediación de un intercambio intel ectual productivo hemos accedido a una recolección cuidaday apropiada del pensamiento de hoy día sobre las condiciones del saber y las acciones que lo implican en los sistemas académicos y educativos en general. Esta recolección realizada por mi colega Dr. Juan Z apata ha permitido poner algunos parámetros para pensar escenarios relevantes en la orientación de nuestro trabajo académico, intelectual, educativo, bajo el rótulo dela reflexión postmoderna.

Entiéndase que esta manera de nombrar a un conjunto de prácticas propias del campo disciplinario que llamamos área de investigación teatral obedece a

* Esta presentación es parte del trabajo realizado al interior del G rupo de Investigación de Literatura Chilena, en el contexto del M ECESU P 0203, dirigido por el Prof. Dr. Gilberto Triviños. 
una intención dialógica que ha resultado productiva para el propósito de dar a conocer lo que hemos estado haciendo por más de una década en el campo de los estudios literarios al interior del D epartamento de Español.

El dispositivo de escena quehemos desarrollado y aplicado en nuestro trabajo de estudio del campo teatral se muestra como un buen instrumento para pensar e instalar condiciones educativas más inmediatistas, con predominio de la presencia, o digamos con aceptación de la presencia en el espacio de la clase. La interrogación al cuerpo del sujeto de la escena puede traernos a presencia materiales reales de unas condiciones a las que de otro modo no tendríamos acceso. Esto permite iluminar una historia personal y colectiva la que estamos en vías de decodificar para que los movimientos en los diferentes escenarios estén llenos de sentido, estén despiertos.

Se requiere que surja la diferencia y multiplicidad en el ámbito educativo de una manera multidimensional que pueda lidiar con el caos, que admita la no lineal idad de la historia y del tiempo, queajuste su discursividad y las estrategias del saber a las personas concretas en un lugar y situación específicos. Cuando digo caos, me refiero a la posibilidad de abandonar las categorías rígidas de la ocurrencia de lo real para dejar entrar unas combinatorias y apariciones subjetivas de una complejidad indescifrable de buenas a primeras.

Son caóticas o complejas en este sentido las pinturas de M agritteo de Echer, en tanto que destruyen ciertas convenciones de percepción de la realidad y con ello las nociones de cuerpo que conoce, de ojo queve, de aparato perceptivo. La subjetivación del mundo que implica reconocer que el ojo es la ventana y a la vez la imagen del paisaje tiene consecuencias que afectan a la noción misma de conocimiento y a la tan socorrida dualidad del sujeto y el objeto.

Rodrigo Pérez señaló, en el seminario de teatro chileno realizado en la U niversidad deC hile el año $2003^{1}$, una secuencia de palabras que desde el punto de vista del creador-director tuvieron una gran fuerza reflexiva. El dijo, cuando se le preguntó por el estilo desu dirección, queen su trabajo artístico seguramente había una impronta. Esta impronta, según él, era su caligrafía y su caligrafía era su biografía. Si seguimos esta idea vamos a dar al hecho de que no se puede

\footnotetext{
${ }^{1}$ Seminario D ramaturgia. Teoría y Escena Teatral en Chile, 5-6 de noviembre 2003, De partamento de Literatura, Facultad de Filosofía y H umanidades de la U niversidad de Chile. Este seminario fue interdisciplinario y yo fui invitada a dar una conferencia "La fiesta de la presen cia: Escenas teatrales desde Concepción". Participaron dramaturgos, directores, acadé micos, estudiantes. D e la U niversidad de Concepción leyeron ponencias Patricia H enríquez, Carolina M uñoz y Karina Pardo. Este seminario nos permitió ubicar nuestro trabajo en el plano teatral de Santiago y comprender que nuestras proposiciones están abriendo un camino propio de avanzada en Concepción, en la producción de conocimiento, en las prácticas educativas relacionadas con el teatro y en la estimulación de la creación dramatúrgico-teatral.
} 
separar el objeto del sujeto y entonces las categorías dentro-fuera (como entidades dicotómicas irreconciliables) están en permanente explosión 0 al menos requieren de un particular tratamiento dada su movilidad. Como medida saludable sería conveniente, al menos, el reconocimiento de este dinamismo que en la trayectoria de cada quien se manifiesta como una escritura, como letra 0 como cuerpo-letra, que susurra o grita una biografía.

¿Q ué es la memoria desde este punto de vista? ¿Q uién construye el relato de nuestras vidas? En cada caso una voz, en cada instancia un parlamento, y afuera de eso, un espectador posible, nosotros mismos asistiendo a nuestro teatro interno-externo. Aquí y ahora la escena del saber literario, del saber con la literatura nos muestra su eficacia en su reaparición en dicha escena.

U na escena lírica puede darnos un buen ejemplo de cómo ocurre la explosión de un sujeto del saber. En el mes de noviembre del año 2003 hemos asistido a un seminario sobre H uidobro dictado por el profesor C edomil Goic. Este investigador asigna a $\mathrm{H}$ uidobro el rol de fundador del lenguaje poético de las vanguardias latinoamericanas. El ha propuesto la lectura de H uidobro y además nos ha entregado la obra poética de H uidobro editada, es decir, acompañada de un aparato crítico y filológico indispensable en la perspectivización de esa obra y de ese momento, en este momento, en este presente.

Retomar el tema de las vanguardias a la luz de la teoría postmoderna, situando al sujeto de Altazor en una escena del saber, nos permite visualizar una definición más nítida de las operaciones que se han llevado a efecto en el campo literario y artístico en general en la época contemporánea. No es que estemos haciendo un descubrimiento sobre qué significa la escritura de H uidobro, sino que en la perspectiva del tiempo es posible distinguir unas escenas que hoy muestran la lucidez de una visión más nítidamente.

Así, Altazor ${ }^{2}$ es un texto que propone una unidad poética capaz de incluir en su interior la fragmentación tanto en el universo representado como en la representación misma. Este rasgo caracteriza la destrucción del lenguaje poético realizada a través de la investigación poética de los creadores vanguardistas y permitetambién ejemplificar una forma artística que responde en al guna medida a los rasgos de lo que se ha dado en llamar postmodernidad.

Altazor, narrador y protagonista de un viaje, realiza un desplazamiento expe rimental intentando explorar el espacio de su propia conciencia. Esta concien-

${ }^{2}$ Un fragmento deAltazor tiene una primera publicación en 1921 en un diario de M adrid. El título Altazor se producehacia 1928. EI nombreoriginal era Alazur. EI C anto IV corresponde a los poemas publicados como "Venus" en 1926 en Francia y "Poema" en Chile el mismo año. Ver VicenteH uidobro. 0 bra poética. Edición crítica, Cedomil G oic. Santiago: EdicionesU. Católica, 2003. 
cia tiene los límites de la muerte y de la temporalidad, pero está compelida a la ruptura de esos límites en su ansia de infinito. El viaje narrado no tiene una estructura lineal ascendente o descendente sino que incluye el subir y el bajar al mismo tiempo, creando una tensión particular que pone en crisis el lenguaje tanto en su forma como en su contenido.

Los recursos innovadores mediante los cuales se actualiza la representación ponen en crisis la categoría de persona; el narrador es poeta, es mago, es animal, es pájaro, etc., lo cual modifica la noción misma del discurso. El sujeto de la enunciación se somete a un progresivo proceso de fragmentación, renunciando a la coherencia y al sentido.

En el proceso de transmutación que se lleva a cabo emerge una nueva jerarquización del orden de lo orgánico. Así,

\section{A la hora del cuerpo en el naufragio ambiguo}

Yo mido paso a paso el infinito.

En el nuevo orden el ojo entra en escena. El ojo media entre la realidad corporal interna del nuevo cuerpo-sujeto y el exterior hacia en cual se asoma.

Por eso hay que cuidar el ojo, precioso regalo del cerebro.

El canto anuncia clausura de la tierra. Lo queforma parte del cambio profetizado en las condiciones del cuerpo nuevo que estará disponible para "ver lo que hay que ver". La clausura de la tierra implica la destrucción de la identidad vieja y el advenimiento de una nueva forma que incluye la duda, la ambigüedad y el humor.

El pájaro tralalí canta en las ramas del cerebro

porque encontró la clave del eternifrete

Rotundo como el unipacio y el espaverso

Uiu uiui

Tralalí tralalá

Aia ai ai aaia i i

La nueva expresión se manifiesta como bal buceo, como el origen de un nue vo lenguaje cuya fuente es el cerebro. Se produce una descarnalización que afecta al sujeto y a su lenguaje que empieza a modularse de acuerdo a nuevas leyes. Es el delirio, la disolución de la razón mortal y el acceso a la eternidad.

$\mathrm{H}$ uidobro inicia la postmodernidad, al fundar una nueva manera de concebir el lenguaje poético y dar con ello alimento y forma a las creaciones que ocurren después de la explosión de al gunas nociones del ser, del ser poético, del ser del lenguaje lírico.

El ser mismo aparece o desaparece en una compleja red de palabras que 
revelan su inexistencia (herida como dirá otro poeta sin imaginarse todavía el monto del daño). Está por verse en la instancia de esa herida, qué ha quedado después de la explosión y cómo se ha rearmado. Q ué se ha rearmado, que se está rearmando constantemente, lo podemos verificar con cierta facilidad si damos el salto de la pregunta por el ser en general a la pregunta por el ser que protagoniza y mueve las transacciones comerciales de la guerra.

Pero, volvamosa nuestro pacífico sujeto lírico más o menosa salvo de amtrax y afines, pero no a salvo de la disolución del lenguaje que diluye también su unidad de ser. D esarma su exal tado yo proveniente del siglo XIX poético, protagonista de un heroísmo romántico e ideal ista en lucha contra la sociedad, contra la costumbre, contra la rutina, contra la convención. Ese yo peligrosamente investiga en los márgenes de la locura, los de la exaltación y de la rebeldía, tal vez, con la insana pretensión de escapar de sí mismo.

L a rosa es siempre rosa e idéntica a sí misma, pero a la vez inal canzable (dice Borges), pero la flor atómica (el hongo en realidad) ya es otra cosa. Entonces, cambian las condiciones mismas del jardín edénico, cuya pérdida tantas veces lamentada ahora se hace imposible de recordar siquiera. Además están D arwin y compañía.

Cuando nos preguntamos qué es la patria chilena, qué es la literatura chilena en ese ejercicio fatigado (como diría Borges) de buscar respuestas en las palabras, con las palabras, en las representaciones de la fantasía, ocurre que una escritura del año '22 un comentario del año '81 vienen a coincidir en una reflexión que nos pone en la presencia, nos conmina a asumir una escena en la que estamos comprometidos con un saber, con una práctica de ese saber en el que, según Patrick Slattery (1995), citando a Huebner, "casi se ha asumido que si un educador puede especificar claramente sus metas, entonces ha llenado o satisfecho su responsabilidad como un ser histórico. Pero la responsabilidad histórica es demasiado compleja como para ser tan fácilmente despachada".

Esta cita pone de relieve la necesidad de reponer, volver a poner lo que es pertinente a la escena educativa contemporánea y redefinir aquello para lo cual ya podríamos estar listos y que se ha estado gestando largamente en un proceso que hemos pretendido ilustrar de al guna manera con nuestro trabajo hoy día y que Slattery describe de manera tal que abre para nosotros un territorio posible real adecuado al tiempo, con el tiempo. Dice él:

El currículo postmoderno estimula el caos, lo no racional y las zonas deincerteza, porque el complejo orden existente en la sala de clases y en las personas humanas es el lugar donde el pensamiento crítico, la intuición reflexiva y la solución de problemas globales florecerán (Slattery, 1995: 620). 
El currículo postmoderno, por otra parte se basa en una nueva ciencia: un sistema complejo, multidimencional, kaleidoscópico, relacional, interdisciplinario y metafórico (Slattery, 1995: 623).

Esa visión ha sido puesta tempranamente en la escritura poética de H uidobro, y está presente en nuestras aproximaciones a la escena educativa local que recogen las visiones de los creadores teatrales contemporáneos, entre ellos el maestro Antonin Artaud, para cumplir el desafío de recobrar la presencia, recobrarnos en la presencia, recuperar nuestro presente, el presente como la instancia única del ser y por ello de nuestro propio cuerpo siendo.

Retomemos algunos hilos, tenemos un saber puesto en perspectiva en una escena relativizada cuyo sistema de anclaje requiere una noción de cuerpo. También tenemos un cuerpo en la escena lírica ${ }^{3}$ de $\mathrm{H}$ uidobro, fragmentado, desterritorializado. Y hay cuerpo en la escena teatral permitiendo una operación que M arco Antonio de la Parra describe así:

El teatro enseña. No sólo muestra (o denuncia o informa), sino que obliga a conocer más que a reconocer aunqueestas dos palabras terminen, al finalísimo minuto de la verdad, siendo la misma. D ispone ojos donde hay ceguera, abre una brecha donde había un muro, actúa como sangría más que como emplasto, contieneel dolor que no tenía cura, otorga garganta abierta a los mudos. Es milagroso, puede llegar a hacernos oír aquello para lo cual éramos sordos. Y ver (C omunicación personal, 2004).

Las funciones del teatro tienen que ver con las funciones corporales que pueden ser restituidas por su intermedio. Esto implica que los cuerpos que se exponen a la experiencia del teatro como creadores, actores 0 espectadores pueden sufrir una transformación que redefine sus sentidos, los despierta en una forma diversificada y compleja4.

Estas operaciones con el cuerpo no son atributo exclusivo del teatro, aunque sí la escena teatral es un lugar privilegiado para la ocurrencia de toda forma de transfiguraciones. En la historia del discurso dialógico que se remonta a la sátira menipenea encontramos escenas que hacen entrar al cuerpo individual y social, el

${ }^{3}$ La escena teatral de Huidobro comparte estos rasgos y establece los fundamentos del teatro chileno contemporáneo. $\mathrm{H}$ an realizado investigación en la producción teatral deH uidobro Pedro Aldunate y N idia Jara, año 2003, en Seminario de Teatro Chileno Contemporáneo que ofrecí en el programa deM agíster en Literaturas H ispánicas del D epartamento deEspañol de la Universidad de Concepción. Estos trabajos examinan diferentes aspectos del lenguaje teatral de vanguardia.

${ }^{4}$ Trabaja en el tema de las escenas teatrales corporales C arolina M uñoz, quien hace su tesis de $M$ agíster en Extasis de Ramón G riffero. 
cuerpo político y filosófico, el cuerpo menesteroso y el opulento en una escritura que poneen cuestión los órdenes establecidos. Luciano de Samosata no dejó afuera de sus escenas dialógicas ni lo cotidiano, ni lo vergonzoso, ni lo ridículo, ni lo grotesco.

Recogiendo esa tradición, hoy día Peter Sloterdijk (1989)recolecta los componentes de la razón cínica y realiza un diagnóstico de la historia humana a través del examen de partes y gestos corporales. La boca fruncida de disgusto, la lengua sacada burlescamente, la boca que ríe desenfadada, las comisuras caídas del desencanto y amargura, delata un cuerpo que dice más de lo que habla, dando señales de un cuerpo que traiciona la mentira del decoro verbal, ofreciendo una historia propia que desespera por entrar en escena.

Las escenas teatrales chilenas contemporáneas exploran los diversos territorios corporales al modo de Galemiri ${ }^{5}$, por ejemplo.

Los cuerpos son puestos en acción apretando los botones del deseo y la ambición pero su eficacia es momentánea y no se constituye ningún destino trágico. Lo risible de la caricatura es la tónica de la escena a ratos esperpéntica, pero sobre todo robótica. El Edipo Asesor es una traducción contemporánea de la escena familiar y dela escena del poder figurada en Atenas por Sófocles. Sófocles reflexiona sobre el destino y el individuo, pero en esa reflexión se exhibe, lateralmente, el modo de ejercicio del poder político. Galemiri muestra la precariedad de los lugares de poder y los trasfondos lúbricos del ejercicio administrativo y político (C ontreras et al., 2003: 22).

El cuerpo del deseo, el cuerpo torturado, el cuerpo entrenado conscientemente para fines específicos, el cuerpo de la costumbre, el cuerpo envejecido, el cuerpo místico, el cuerpo adolescente, el cuerpo de la mujer, el cuerpo del hombre, el cuerpo homosexual, el cuerpo enfermo, constituyen una serie que entra en el teatro chileno contemporáneo en las obras de G riffero, Galemiri, D e la Parra, Radrigán, etc., con un rico despliegue de poéticas teatrales que estamos en vías de conocer y describir.

La cuestión de la escena, y del cuerpo en escena conectada con un proyecto que he llamado por añosel proyecto educativo chileno, obtienesu materialización en los estudios del área teatral del Departamento de Español, en la cual los jóvenes investigadores amplían el campo de experiencia cognoscitiva y de escritura a través de un trabajo acorde con los tiempos y los desafíos propios de una cultura que ha cambiado, que está cambiando. Esto nos obliga a repensar nues-

${ }^{5}$ Está realizando una investigación de los procedimientos dela escritura teatral de G alemiri, Karina Pardo, quien escribe su tesis de M agíster en Literaturas H ispánicas sobre dos obras del dramaturgo. 
tras concepciones de la realidad, de la literatura, del conocimiento, del cuerpo del conocimiento con la esperanza de realizar una práctica apropiada en el área de los estudios literarios, en el área de formación de profesores que pueda tener incidencia al hacer entrar el cuerpo en la escena educativa local.

\section{REFERENCIAS}

Contreras, M arta, Patricia H enríquez y Adolfo Albornoz. 2003. Historiasdel Teatro de la Universidad de Concepción (TUC). Concepción, Chile: Editorial Universidad de Concepción.

Goic, Cedomil. 2003. Vicente H uidobro. 0 bra poética. Santiago, C hile: Ediciones de la U niversidad Católica.

Slattery, Patrick. 1995. "A Postmodern Vision of Time and Learning: A Response to the National Education Commission Report Prisoners of Time", in Harvard Educational Review Vol. 65, Number 4, pp. 612-633.

Sloterdijk, M eter. 1989. Crítica de la razón ć́nica. M adrid: Taurus.

Zapata, Juan. 2003. "Los estudios literarios en América Latina". D ocumento de Trabajo del G rupo deInvestigación de LiteraturaChilena. Universidad deC oncepción, Chile. 